\title{
Infecções intramamárias causadas por Staphylococcus aureus e suas implicações em paúde pública
}

\author{
Staphylococcus aureus intramammary infections and its implications in public health
}

\author{
Helena Fagundes ${ }^{1}$ Carlos Augusto Fernandes Oliveira ${ }^{2}$
}

\section{- REVISÃO BIBLIOGRÁFICA -}

\section{RESUMO}

Neste trabalho, são apresentados os principais problemas decorrentes das infecções intramamárias (mastites) causadas por Staphylococcus aureus e as conseqüências para a saúde humana da veiculação de suas toxinas através do leite. O S. aureus destaca-se como um dos microorganismos mais importantes que podem ser transmitidos através dos alimentos. Assim, discute-se a possibilidade de veiculação de gastroenterite estafilocócica, não somente através do consumo de leite cru contaminado, mas também de leite tratado termicamente ou de derivados lácteos contendo enterotoxinas termoestáveis. São apresentados alguns aspectos relacionados ao potencial toxigenico das cepas de $\mathbf{S}$. aureus, bem como as principais características das enterotoxinas estafilocócicas. Considerando que o $\mathbf{S}$. aureus é um dos agentes de mastite mais freqüentemente observados, apresentam-se as principais medidas de controle de infecções estafilocócicas em rebanhos leiteiros, com vistas à prevenção da ocorrência de toxinas no leite de consumo.

Palavras-chave: Staphylococcus aureus, enterotoxinas, mastite, saúde humana.

\section{ABSTRACT}

This article presents the main problems derived from the mammary infections (mastitis) caused by Staphylococcus aureus, and the consequences of the presence of its toxins in milk for human health. S. aureus is one of the most important microorganisms that can be transmitted through the food products. Hence, the possibility of transmission of stafilococal gastroenteritis by consumption of raw milk and heat-treated milk, containing heat-resistant enterotoxins, is discussed. Some aspects regarding the toxigenic potential of $\boldsymbol{S}$. aureus strains and the main characteristics of stafilococal entorotoxins are presented. Taking into account that $\mathbf{S}$. aureus is also one of the most prevalent agents of mastitis, considerations are made on the methods for the controlling of stafilococal infections in dairy cattle, in order to prevent the occurrence of toxins in milk and milk products.
Key words: Staphylococcus aureus, enterotoxins, mastitis, human health.

\section{INTRODUÇÃO}

O leite e seus derivados desempenham um papel nutricional importante para o homem, particularmente nos primeiros anos de vida, uma vez que fornecem proteínas, carboidratos, gorduras e sais minerais necessários ao desenvolvimento do organismo. Sabe-se que um litro de leite por dia supre todas as necessidades protéicas de crianças com até seis anos de idade e mais de $50 \%$ do conteúdo de proteínas requisitado pelos adultos. Em relação ao cálcio, o consumo de um litro de leite diário supre $100 \%$ das necessidades diárias deste mineral (FONSECA \& SANTOS, 2000). É de se esperar, portanto, uma grande preocupação em assegurar a integridade e a qualidade intrínseca do leite e dos produtos lácteos destinados ao consumo humano.

A qualidade do leite assume destacada importância também sob o ponto de vista de Saúde Pública. No Brasil, embora não existam estatísticas disponíveis sobre o assunto, são freqüentes os casos de doenças associadas ao consumo de leite cru ou de derivados produzidos com leite contaminado com microrganismos patogênicos. Contribui para isto, entre outras causas, o fato de mais de $44 \%$ do leite consumido no país ser proveniente do mercado informal (ANUÁRIO MILKBIZZ, 1999), ou seja, comercializado sem qualquer tratamento térmico ou controle laboratorial.

\footnotetext{
${ }^{1}$ Médico Veterinário, Aluna de Mestrado do Programa de Pós-graduação em Qualidade e Produtividade Animal, Faculdade de Zootecnia e Engenharia de Alimentos, Universidade de São Paulo (USP).

${ }^{2}$ Médico Veterinário, Professor Associado, Faculdade de Zootecnia e Engenharia de Alimentos, USP. Av. Duque de Caxias Norte 225, 13630-000, Pirassununga, SP, Brasil. E-mail: carlosaf@usp.br. Autor para correspondência.
} 
Dentre os diversos tipos de microorganismos patogênicos que podem ser transmitidos através do leite e derivados, destaca-se o Staphylococcus aureus, cuja importância na epidemiologia das doenças veiculadas por alimentos decorre de sua alta prevalência e do risco de produção, nos alimentos contaminados, de toxinas causadoras de gastrenterites alimentares (ZECCONI \& HAHN, 2000).

A contaminação microbiológica dos alimentos tem sido objeto de preocupação constante em diversos países. Nos Estados Unidos da América (EUA), estima-se que, anualmente, entre 1 a 2 milhões de pessoas são acometidas por gastrenterites provocadas por toxinas de $\boldsymbol{S}$. aureus presentes, sobretudo, em produtos de origem animal (JAY, 1994). No Brasil, segundo dados do Ministério da Saúde, foram registrados 593.212 casos de intoxicação alimentar entre 1984 e 1997, porém sem especificar as toxinas, os microrganismos ou as fontes envolvidas (MINISTÉRIO DA SAÚDE, 1999). Estes dados, possivelmente subestimados devido à falta de notificação dos surtos, demonstram a relevância das medidas de controle sanitário dos alimentos destinados ao consumo humano, particularmente das matérias primas de origem animal.

\section{IMPORTÂNCIA DO S. AUREUS COMO AGENTE DE MASTITES}

Sabe-se que o principal problema que afeta os rebanhos leiteiros, mundialmente, é a inflamação da glândula mamária ou mastite, a qual, frequientemente, tem origem bacteriana (COSTA et al., 1995; LANGONI et al., 1998; NATIONAL MASTITIS COUNCIL, 1996). Mais de 80 diferentes microrganismos foram identificados como agentes causadores de mastite bovina, sendo que as espécies mais freqüentemente isoladas são Staphylococcus aureus, Streptococcus agalactiae, Streptococcus dysgalactiae, Streptococcus uberis e Escherichia coli (HARMON, 1994).

A mastite é considerada como a doença que proporciona as maiores perdas econômicas na produção de leite. Estima-se que haja um prejuízo de cerca de US $\$ 1,8$ bilhões/ano nos EUA, em função da ocorrência de mastites (NATIONAL MASTITIS COUNCIL, 1996). No Brasil, estima-se que, em função da alta prevalência de mastite nos rebanhos, possa ocorrer perda de produção entre 12 e 15\%, o que significa um total de 2,8 bilhões de litros/ano em relação à produção anual de 20 bilhões de litros (FONSECA \& SANTOS, 2000).
De acordo com o Conselho Nacional de Mastite dos EUA, rebanhos leiteiros que não adotam medidas de controle para mastite apresentam cerca de $50 \%$ das vacas infectadas, em média, em dois quartos (NATIONAL MASTITIS COUNCIL, 1996). As estimativas brasileiras apontam valores de $20 \%$ (LANGENEGGER et al., 1970), 38\% (FONSECA, 1992), e até $71 \%$ para a prevalência da doença em rebanhos dos estados de Minas Gerais e São Paulo (COSTA et al., 1999).

Neste cenário, o Staphylococcus aureus destaca-se como o microorganismo causador de mastite contagiosa de maior importância, de maior ocorrência nos rebanhos mundiais, e de tratamento mais difícil devido à elevada resistência aos antibióticos. Coerentemente, o $\boldsymbol{S}$. aureus é, também, o microrganismo patogênico mais freqüentemente isolado no leite cru (ZECCONI \& HAHN, 2000). Em levantamentos epidemiológicos nacionais e internacionais, o $\boldsymbol{S}$. aureus está presente em cerca de $50 \%$ das infecções da glândula mamária dos bovinos leiteiros (BRABES et al., 1999). BRABES et al. (1999), analisando 127 amostras de leite de cinco propriedades leiteiras dos estados de São Paulo e Minas Gerais, encontraram uma prevalência de 40,15\% para a espécie $S$. aureus. Neste mesmo estudo, verificou-se que houve predomínio de bactérias do gênero Staphylococcus na etiologia da mastite em três propriedades, com percentuais de positividade entre 32 e $80 \%$. Considerando o isolamento de 16 cepas produtoras de enterotoxinas, os dados obtidos no referido trabalho indicam um risco potencial à saúde humana associado ao consumo do leite dos rebanhos analisados, uma vez que a maioria dos casos diagnosticados de mastite era do tipo subclínico, ou seja, de animais que não apresentavam alterações visíveis na glândula mamária e tampouco no leite.

Entre as características morfo-fisiológicas do S. aureus, destacam-se as seguintes: são cocos Gram positivos, coagulase positivos, $\beta$ - hemolíticos, maltose e manitol positivos e formadores de colônias pigmentadas (JAY, 1994). Podem apresentar polimorfismo, o que acarreta muitos problemas para o controle das infecções porque afetam diretamente o sistema imunológico da vaca e sua suscetibilidade às infecções (ZECCONI \& HAHN, 2000). O S. aureus é classificado como microorganismo mesófilo, porém, pode apresentar crescimento em temperaturas compreendidas entre 7,0 e 47,8 ${ }^{\circ}$ C (JAY, 1994). As enterotoxinas estafilocócicas, por outro lado, são produzidas entre 10 e $46^{\circ} \mathrm{C}$, (SMITH et al., 1983) e apresentam elevada resistência térmica, podendo sobreviver aos tratamentos térmicos comumente aplicados ao leite, como a pasteurização. 
O leite é um meio de cultura ideal para os microorganismos em geral, por apresentar uma composição quase perfeita como alimento. Assim, a multiplicação dos microrganismos é muito rápida, se a temperatura for ideal para o crescimento (COUSINS \& BRAMLEY, 1987). A contaminação microbiana do leite pode ocorrer por duas vias principais: através da incorporação de microorganismos que estão presentes no úbere, diretamente para o leite; ou através do contato do leite com utensílios e equipamentos contaminados durante as operações de ordenha ou da coleta e armazenamento (FEHLHABER \& JANESTSCHKE, 1995). A contaminação do leite com $S$. aureus pode ocorrer através das duas vias, uma vez que se trata de um microrganismo patogênico que pode causar inflamações no úbere das vacas, além de estar presente em superfícies de utensílios e equipamentos de ordenha (FONSECA \& SANTOS, 2000). Neste último caso, deve-se ressaltar a importância do homem como reservatório de $S$. aureus e principal veiculador do microrganismo em alimentos, de modo geral (JAY, 1994). Com relação à identificação da origem do $\boldsymbol{S}$. aureus no leite de consumo, diversos métodos bioquímicos e moleculares têm sido utilizados para diferenciar as cepas provenientes de infecções humanas e animais. A técnica de PCR associada à ribotipagem tem-se mostrado bastante útil para esta finalidade, devido à sensibilidade e rapidez, possibilitando o monitoramento de cepas e o estudo taxonômico molecular (PEREIRA et al., 2002).

O $S$. aureus é amplamente distribuído nos rebanhos leiteiros, sendo que a probabilidade de contaminação do leite cru com a conseqüente produção de enterotoxinas é bastante elevada. Em bovinos, KENNY et al. (1993) relataram que, no mínimo, 28,6\% das cepas isoladas do úbere secretam uma ou mais toxinas. MATSUNAGA et al. (1993), no entanto, encontraram $34,5 \%$ de cepas enterotoxigênicas. Em cabras, a ocorrência é ainda maior, a julgar pelos dados apresentados por VALLE et al. (1990), os quais obtiveram 48,8\% de cepas toxigênicas de $S$. aureus isoladas diretamente do leite.

Em um estudo conduzido no Brasil por MARIANO et al. (2002), foram coletadas 184 amostras de leite caprino, das quais foram isoladas $36(19,6 \%)$ contendo bactérias enterotoxigênicas do gênero Staphylococcus, sendo 14 delas $(38,8 \%)$ positivas para a espécie $S$. aureus. Os autores concluíram que as enterotoxinas produzidas permanecem no leite pasteurizado graças à sua termoestabilidade, tornando-se um risco em potencial à saúde dos consumidores de leite de cabras.
Não existem estudos conclusivos sobre a relação entre características das cepas e sua toxigenicidade. No entanto, MATSUNAGA et al. (1993) sugeriram que a produção de toxinas seria mais freqüentemente observada em cepas de maior patogenicidade.

\section{CARACTERÍSTICAS DAS TOXINAS PRODUZIDAS POR S. AUREUS}

As enterotoxinas produzidas pelo $S$. aureus pertencem a uma grande família de toxinas pirogênicas produzidas tanto por bactérias do gênero Staphylococcus, como Streptococcus. Estas toxinas podem causar choque tóxico e estão comumente associadas com intoxicações alimentares e diversas formas de alergias e doenças autoimunes (BALABAN \& RASOOLY, 2000).

Os sinais observados na maioria dos casos de gastrenterite estafilocócica inclui náuseas, vômitos, contrações abdominais, diarréia, sudorese e cefaléia. A intoxicação geralmente não é letal, sendo que a duração dos sintomas é de 1 a 2 dias, podendo evoluir para quadros mais severos, dependendo da susceptibilidade do indivíduo. O período de incubação varia de 1 a 6 horas após a ingestão do alimento contaminado, com média de 4 horas (BALABAN \& RASOOLY, 2000).

De acordo com EVENSON et al. (1988), a quantidade mínima de enterotoxina estafilococócica necessária para causar sintomatologia em humanos é de 200ng. Este valor foi estimado a partir de um surto de gastrenterite atribuído a leite achocolatado, cujas amostras revelaram enterotoxina A no nível médio de $144 \mathrm{ng}$ /embalagem. No episódio, crianças com idade de 5 a 9 anos mostraram maior sensibilidade do que adolescentes de 10 a 19 anos de idade. Calculase que, para produzir intoxicação no homem, sejam necessários de 15 a 357ng de enterotoxina por kg de peso corporal (YI \& LEE-WONG, 1997).

A produção de enterotoxinas não está restrita à espécie $\boldsymbol{S}$. aureus. Estudos evidenciaram espécies coagulase negativas, capazes de produzir toxinas em condições laboratoriais, como $S$. xylosus, $S$. haemolyticus, S. epidermidis, S. cohnii, S. chromogenes, S. warneri, S. sciuri e S. lentus (PEREIRA et al., 2001). Este fato demonstrou que outras espécies de Staphylococcus, além de S. aureus, são capazes de produzir enterotoxinas, embora esta característica já tivesse sido relatada, também, para outras espécies coagulase positivas, como $\boldsymbol{S}$. hyicus e $\boldsymbol{S}$. intermedius (VALLE et al., 1990).

Com base em métodos sorológicos, identificam-se sete enterotoxinas estafilocócicas, 
denominadas A, B, $\mathrm{C}_{1}, \mathrm{C}_{2}, \mathrm{C}_{3}$, D, E, G, H e I (DINGES et al., 2000). São proteínas simples, resistentes à hidrólise pelas enzimas gástricas e jejunais, e são estáveis ao aquecimento a $100^{\circ} \mathrm{C}$ durante 30 minutos, não sendo inativadas totalmente pela cocção normal, pasteurização e outros tratamentos térmicos usuais (JAY, 1994). A enterotoxina do tipo A é a mais freqüentemente associada à gastrenterite estafilocócica.

A capacidade de produzir uma ou mais enterotoxinas é encontrada em 30 a 50\% das cepas de S. aureus (CARDOSO et al., 2000). MASUD et al. (1993), ao examinar 48 linhagens enterotoxigênicas de S. aureus, isoladas de produtos lácteos, observaram que pelo menos 16 delas produziram mais de um tipo de enterotoxina. A enterotoxina mais comumente encontrada foi a do tipo A (em 37, 7\% do total de isolados), seguida pelo tipo B $(17,7 \%), \mathrm{D}(11,8 \%) \mathrm{e}$ $\mathrm{C}(10,6 \%)$.

A produção simultânea de diferentes tipos de toxinas pode aumentar os seus efeitos toxigênicos isolados, sugerindo que essa co-produção possa desempenhar papel importante na patogenia das infecções intramamárias produzidas por esse microrganismo. REFAI et al. (1998) demonstraram que existe associação entre a atividade enzimática específica, a enterotoxigenicidade e a resistência de S. aureus a vários antibióticos, principalmente naquelas amostras produtoras de mais de um tipo de enterotoxina.

As bactérias do gênero Staphylococcus produzem, também, uma grande variedade de toxinas extracelulares e de fatores de virulência, os quais estão relacionados à patogenicidade e aos mecanismos de resistência aos antimicrobianos disponíveis. Entre esses, destaca-se a toxina 1 da síndrome do choque tóxico (TSST-1), reconhecida como a principal causa da síndrome do choque tóxico (TSS) em seres humanos, caracterizada por febre, hipotensão, congestão em vários órgãos e choque letal (CARDOSO et al., 2000). A TSST-1 é um polipeptídeo de cadeia simples, com propriedades biológicas comuns a outras exotoxinas pirogênicas e superantigênicas (DINGES et al., 2000), como capacidade de induzir febre, aumentar a letalidade do choque endotóxico, estimular a proliferação inespecífica de células $T$ e induzir a produção de interleucina-1, de gama interferon e do fator alfa de necrose tumoral (ELLIS et al., 1993).

O primeiro relato de detecção de TSST-1 produzida por Staphylococcus spp. de origem animal foi feito por JONES \& WIENEKE (1986). Estudos recentes, realizados com $\mathbf{S}$. aureus isolados de casos clínicos e subclínicos de mastite bovina, demonstraram que entre $20 \%$ e $77 \%$ dos isolados produziram TSST-1 e enterotoxinas estafilocócicas. Em tanques de expansão utilizados para resfriamento e armazenamento de leite, $75,4 \%$ das amostras de $\boldsymbol{S}$. aureus isoladas demonstraram capacidade de produzir essas toxinas (TAKEUCHI et al., 1998).

Em trabalho realizado por CARDOSO et al. (2000), de um total de 127 amostras isoladas de mastite bovina, 83 (65\%) apresentaram produção de pelo menos um tipo de toxina, isolado ou em combinação. Algumas amostras eram produtoras de até quatro toxinas diferentes ao mesmo tempo. Apenas $35 \%$ das amostras testadas foram negativas para qualquer tipo de toxina produzida. Das toxinas identificadas neste trabalho, houve predomínio da TSST-1 e da enterotoxina D, em relação às outras enterotoxinas estafilococócicas. Outros pesquisadores, entretanto, associam TSST-1 e a enterotoxina C à amostras causadoras de mastites agudas e subclínicas em bovinos (JONES \& WIENEKE, 1986; MATSUNAGA et al., 1993; TAKEUCHI et al., 1998).

$A$ presença de enterotoxinas estafilococócicas no leite e nos produtos lácteos tem sido constatada em diversos estudos. ROSEC et al. (1997), analisando queijos elaborados com leite cru, observaram a presença de toxina do tipo $\mathrm{C}$ em $73,7 \%$ das 61 amostras analisadas.

$\mathrm{Na}$ Inglaterra, BONE et al. (1989) relataram que queijos fabricados com leite de ovelhas foram responsáveis por casos de intoxicação alimentar, sendo que as amostras de queijos revelaram a presença de enterotoxina $\mathrm{A}$. Após a realização de análises complementares em amostras de leite e de queijos, os autores concluíram que a contaminação por $\boldsymbol{S}$. aureus ocorreu devido a algum tipo de infecção sofrida pelos animais na fazenda, e não no processo de elaboração dos queijos.

NG \& TAY (1993), estudaram amostras de leite fresco contaminado com $S$. aureus coagulase positivo. A presença de cepas de $\boldsymbol{S}$. aureus produtoras de enterotoxinas foi constatada em $32,45 \%$ dos isolados, os quais produziram $29,7 \%, 36,1 \%, 22,2 \%$ e $16,7 \%$ das enterotoxinas do tipo B, C, D e A respectivamente.

No que concerne à possibilidade de eliminação das toxinas estafilocócicas dos alimentos contaminados, não foram encontradas referências, na literatura, que atestem a inativação eficiente das mesmas através dos processos usuais de pasteurização ou esterilização industrial do leite e derivados. 


\section{MEDIDAS DE CONTROLE DE INFECÇÕES INTRAMAMÁRIAS}

De acordo com ZECCONI \& HAHN (2000), para reduzir o risco da presença do $S$. aureus e de outros microrganismos indesejáveis no leite cru é necessário implementar medidas para diminuir a prevalência das infecções intramamárias. Deste modo, compete aos setores de captação de leite das usinas e aos serviços de extensão, incrementar o desenvolvimento das atividades de orientação e apoio aos produtores, com a finalidade de aprimorar as técnicas de produção e obtenção do produto, com destaque para os seguintes aspectos importantes (OLIVEIRA et al., 1999): realização de testes periódicos para o diagnóstico individual de casos de mastite clínica nas vacas leiteiras; colheita de amostras e identificação laboratorial dos agentes infecciosos envolvidos nos casos de mastite; descarte do leite de vacas acometidas com infecções causadas por bactérias do gênero Staphylococcus, bem como de outros agentes infecciosos de importância em saúde humana; tratamento adequado dos quartos afetados com antimicrobianos, respeitando-se o intervalo de carência recomendado para a utilização do leite; limpeza e desinfecção criteriosa do úbere dos animais, antes e depois da ordenha; provisão de quantidades suficientes de água potável para os diversos processos de obtenção do leite; e, manutenção dos cuidados de higiene geral do estábulo leiteiro, incluindo a limpeza e desinfecção das instalações de ordenha, ordenhadeiras e utensílios. Com relação às teteiras, a desinfecção após a ordenha de cada vaca é particularmente eficiente para o controle de S. aureus, podendo ser realizada automaticamente (sistema por backflushing) ou através do método manual por imersão das teteiras em balde, desde que tomadas as precauções necessárias, tais como a troca freqüente da solução desinfetante e a imersão das teteiras por tempo suficiente (FONSECA \& SANTOS, 2000).

Deve-se ressaltar, por último, que, tendo em vista a relativa escassez de dados sobre a ocorrência de enterotoxinas estafilocócicas nos produtos de leite, é fundamental a realização de análises microbiológicas periódicas, com vistas à pesquisa de bactérias do gênero Staphylococcus e suas toxinas no leite entregue nas usinas de beneficiamento.

\section{CONCLUSÃO}

As infecções intramamárias causadas por S. aureus apresentam implicações importantes em Saúde Pública, tendo em vista que as toxinas podem ser excretadas no leite e permanecer estáveis nos produtos oferecidos ao consumo. A simples presença de cepas toxigênicas de $S$. aureus no leite não implica, necessariamente, a ocorrência de intoxicações em seres humanos, porém o risco existe e é maior para crianças, principalmente de tenra idade. A percepção de risco é aumentada, principalmente, ao se considerar que esse microorganismo é o mais envolvido nas infecções intramamárias de rebanhos leiteiros, com prevalência de cepas com elevado potencial toxigênico.

Diante destes fatos, torna-se importante prevenir e controlar as infecções intramamárias nos rebanhos para melhorar a qualidade dos produtos oferecidos à população. A oferta de leite de boa qualidade exige uma série de medidas de controle em todas as etapas da cadeia de produção. Da mesma forma, produtores de leite e mercado varejista, membros da indústria leiteira (setor de transformação) devem atender à demanda dos consumidores por qualidade e segurança alimentar.

\section{REFERÊNCIAS BIBLIOGRÁFICAS}

ANUÁRIO MILKBIZZ. Anuário Milkbizz 1999/2000. São Paulo : Milkbizz, 1999. 326p.

BALABAN, N.; RASOOLY, A. Staphylococcal enterotoxins: a review. Int J Food Microbiol, v.61, p.1-10, 2000.

BRABES, K. et al. Participação de espécies coagulase positivas e negativas produtoras de enterotoxinas de gênero Staphylococcus na etiologia de casos de mastite bovina em propriedades de produção leiteira dos estados de São Paulo e Minas Gerais. Rev Napgama, v.3, p.4-11, 1999.

BONE, F.J.; BOGIE, D.; MORGAN-JONES, S.C. Staphylococcal food poisoning from sheep milk cheese. Epidemiol Infect, v.103, p.449-458, 1989.

CARDOSO, H.F.T.; CARMO, L.S.; SILVA, N. Detecção da toxina - 1 da síndrome do choque tóxico em amostras de Staphylococcus aureus isoladas de mastite bovina. Arq Bras Med Vet Zootec, v.52, p.7-10, 2000

COSTA, E.O. et al. Estudo etiológico da mastite bovina. Rev Bras Med Vet, v.17, p.156-158, 1995.

COSTA, E.O. Resíduos de antibióticos no leite: um risco à saúde do consumidor. Higiene Alimentar, v.10, p.15-17, 1996.

COSTA, E.O. et al. Mastite subclínica: prejuízos causados e os custos de prevenção em propriedades leiteiras. Rev Napgama. v.2, p.16-20, 1999 .

COUSINS, C.M.; BRAMLEY, A.J. Microbiologia de la leche cruda. In: ROBINSON, R.K. Microbiologia lactológica. Zaragoza : Acribia, 1987. Cap.4, p.109-150.

DINGES, M.M; ORWIN, P.M; SCHLIEVERT, P.M. Exotoxins of Staphylococcus aureus. Clin Microbiol Rev, v.13, p.16-34, 2000. 
ELLIS, J.A. et al. Capture immunoassay for ruminant tumor necrosis factor - alpha: comparison with bioassay. Vet Immunol Immunopathol, v.35, p.289-300, 1993.

EVENSON, M.L. et al. Estimation of human dose of staphylococcal enterotoxin A from a large outbreak of staphylococcal food poisoning involving chocolate milk. Int J Food Microbiol, v.7, p.311-316, 1988.

FEHLHABER, K; JANETSCHKE, P. Higiene veterinária de los alimentos. Zaragoza : Acribia, 1995. 669p.

FONSECA, L.F.L. Estudo da prevalência da mastite bovina e sua relação com práticas de manejo, higiene e terapia em fazendas produtoras de leite tipo B no Estado de São Paulo. 1992. 148f. Dissertação (Mestrado em Ciência Animal e Pastagens) - Curso de Pós-graduação em Ciência Animal e Pastagens, ESALQ, Universidade de São Paulo.

FONSECA, L.F.L.; SANTOS, M.V. Qualidade do leite e controle de mastite. São Paulo : Lemos Editorial, 2000. 175p.

HARMON, R.J. Physiology of mastitis and factors affecting somatic cell counts. J Dairy Sci, v.77, p.2103-2112, 1994.

JAY, J.M. Microbiología moderna de los alimentos. Zaragoza: Acribia, 1994. 804p.

JONES, T.O.; WIENEKE, A.A. Staphylococcal toxic shock syndrome. Vet Rec, v.119, p.435, 1986.

KENNY, K. et al. Production of enterotoxins and toxic shock syndrome toxin by bovine mammary isolates of Staphylococcus aureus. J Clin Microbiol, v.31, p.796-707, 1993.

LANGENEGGER, B. et al. Estudo da incidência de mastite bovina na bacia leiteira do Rio de Janeiro. Pesq Agropec Bras, v.5, p.437, 1970 .

LANGONI, H. et al. Aspectos etiológicos na mastite bovina. Rev Bras Med Vet, v.20, p.204-210, 1998.

MARIANO, F.A. et al. Cepas de Staphylococcus spp. enterotoxigênicos isolados de leite caprino. Isolamento e identificação automatizada de cepas de Staphylococcus spp. enterotoxigênicos oriundos de leite caprino. In: ENCONTRO DE INICIAÇÃO CIENTÍFICA, 7, 2002, Campos dos Goytacazes, RJ. Anais... Campos dos Goytacazes : Universidade Estadual do Norte Fluminense, 2002. N.p.

MASUD, T.; ALI, A.M.; SHAH, M.A. Enterotoxigenicity of Staphylococcus aureus isolated from dairy products. Aust J Dairy Technol, n.48, p.30-32, 1993.
MATSUNAGA, T. et al. Characteristics of Staphylococcus aureus isolated from peracute, acute and chronic bovine mastitis. J Vet Med Sci, v.55, p.297$300,1993$.

MINISTÉRIO DA SAÚDE. Sistema de informações hospitalares. Brasília : DATASUS, 1999.

NATIONAL MASTITIS COUNCIL. Current concepts of bovine mastitis. 4.ed. Madison : NMC, 1996. 64p.

NG, D.L.K.; TAY, L. Enterotoxigenic strains of coagulase-positive Staphylococcus aureus in drinks and ready to eat foods. Food Microbiol, v.10, p.317-320, 1993.

OLIVEIRA, C.A.F.; FONSECA, L.F.L.; GERMANO, P.M.L. Aspectos relacionados à produção que influenciam a qualidade do leite. Higiene Alimentar, v.13, p10-16, 1999.

PEREIRA, M.L.; CARMO, L.S.; PEREIRA, J.L. Comportamento de estafilococos coagulase negativos pauciprodutores de enterotoxinas em alimentos experimentalmente inoculados. Ciênc Tecnol Aliment, v.21, p.171175,2001 .

PEREIRA, M.S.V. et al. Typing of human and bovine Staphylococcus aureus by RAPD-PCR and ribotyping-PCR. Lett Appl Microbiol, v.35, p.32-36, 2002.

REFAI, M. et al. Correlation between antibiotic resistance, enterotoxigenicity and enzimatic activities of Staphylococcus aureus recovered from foods. Vet Med J, v.36, p.107-109, 1998.

ROSEC, J.P. et al. Enterotoxin production by staphylococci isolated from foods in France. Int J Food Microbiol, v.35, p.213221, 1997.

SMITH, J.L.; BUCHANAN, R.L.; PALUMBO, S.A. Effect of environment on staphylococcal enterotoxin synthesis: a review. J Food Protec, v.46, p.545-555, 1983.

TAKEUCHI, S. et al. Production of toxic shock syndrome toxin by Staphylococcus aureus isolated from mastitic cow's milk and farm bulk tank. Vet Microbiol, v.59, p.251-258, 1998.

VALLE, J. et al. Enterotoxin production by staphylococci isolated from healthy goats. Appl Environ Microbiol, v.56, p.1323-1326, 1990.

YI, C.S.; LEE-WONG, A.C. Current perspectives on detection of staphylococcal enterotoxins. J Food Protec, v.60, p.195-202, 1997.

ZECCONI, A.; HAHN, G. Staphylococcus aureus in raw milk and human health risk. Bulletin of IDF, v.345, p.1518,2000 . 